\title{
Tonic immobility as a fear response in lizards
}

$$
\text { (Anolis carolinensis)* }
$$

\author{
PATRICIA H. EDSON and GORDON G. GALLUP, JR. \\ Tulane University, New Orleans, La. 70118
}

The role of fear in mediating the immobility response was studied in three experiments with a total of 71 anoles. In the first experiment, a significant relationship between level of preinduction shock and duration of immobility was found. Experiment 2 revealed a significant effect of brief exposure to a loud noise on the resulting duration of immobility. In the third experiment, lizards immobilized in the visual presence of an $E$ showed longer reactions than those immobilized from behind a barrier. The findings were taken as support for a fear interpretation of animal hypnosis.

Although the tonic immobility or hypnotic response has been found in many different species, it has been studied experimentally in only a few. To date, no more than three or four published studies have appeared on lizards. The immobility response in the anole (Anolis carolinensis) was first investigated by Hoagland (1928a, b). Hoagland attempted to manipulate the response chemically and found that injections of adrenalin tended to prolong the immobility episode. A more recent report of tonic immobility by Prestrude \& Crawford (1970) used the lizard, Iguana iguana. They found that the green iguana was a good source for studying animal hypnosis, and, in spite of repeated handling, none of their animals failed to exhibit the response; however, no attempt was made to manipulate the reaction experimentally or to test any hypotheses concerning its significance.

Recently, the idea that tonic immobility may be mediated by fear has received extensive experimental support from work with domestic chickens. These studies (e.g., Gallup, Rosen, \& Brown, 1971) suggest that tonic immobility in the chicken may be an innate fear response which has evolved to meet the demands of predator-prey relationships. The present study represents an attempt to look for comparable effects of experimentally induced fear on immobility reactions in $A$. carolinensis.

\section{EXPERIMENT 1}

The immobility response has been explained by several investigators as an innate fear response (e.g., Ratner \& Thompson, 1960; Salzen, 1963). In support of this interpretation, Gallup, Creekmore, \& Hill (1970) found that

*Appreciation is expressed to T.J. $O$ 'Brien for help in collecting the lizards. Requests for reprints should be sent to the second author. young chickens given electric shock prior to manual restraint remained immobile significantly longer than controls given no shock. In the present study, it was hypothesized that the duration of tonic immobility in the anole would bear a relationship to the amount of preinduction shock, consonant with the fear hypothesis.

The Ss were 39 mature $A$. carolinensis of both sexes which were collected locally. The lizards were captured after dark through the use of head-mounted spotlights to aid detection. Ss were randomly divided into groups of 13 and housed in individual glass bowls. Room temperature was maintained at approximately $70^{\circ}$ and $80^{\circ} \mathrm{F}$ during the dark and light cycles, respectively. The photoperiod in effect throughout consisted of $12 \mathrm{~h}$ of artificial light. Food in the form of meal worms and also water were made regularly available. All Ss were maintained in the laboratory for 1 week prior to testing.

\section{Apparatus}

Testing equipment consisted of a Foringer shock generator (Model 591-14N) wired to two solid copper wires extending $8 \mathrm{~cm}$ from the end of a narrow wooden dowel which measured $28 \mathrm{~cm}$ in length. The copper wires, which were used to administer shock, were parallel and approximately $1 \mathrm{~cm}$ apart at their point of contact with a lizard. The duration of each immobility episode was timed with a stopwatch.

Procedure

Groups were designated randomly as control, low shock, and high shock. To overcome skin resistance, each lizard's back was swabbed with saline solution prior to administering shock. Testing consisted of placing the copper electrodes on the back of a lizard, about halfway between the neck and base of the tail, and applying a 2-sec shock of $0, .15$, or $.80 \mathrm{~mA}$ according to group designation. Immediately after the receipt of shock, each lizard was immobilized on a table by inverting it on its back and maintaining manual restraint accompanied by moderate pressure for $20 \mathrm{sec}$. Manual restraint was applied by placing one finger at the base of the tail and another on the lower jaw. Duration of self-paced immobility was measured from the time restraint was terminated until the righting response occurred, with the $\mathrm{E}$ sitting about $.6 \mathrm{~m}$ away. A 30-min ceiling was imposed on the duration of each reaction as an economy measure. If, for any reason, a lizard did not become immobile following the initial application of manual restraint, it was given successive 20 -sec inductions until a state of immobility obtained.

Results

The results of the first experiment indicate that the duration of immobility was related to intensity of preinduction shock. The mean durations of immobility were 339.6 , 516.2 , and $778.7 \mathrm{sec}$ for control, low-shock, and high-shock groups, respectively. Due to appreciable heterogeneity of variance, raw scores were transformed $\left(\log _{10}\right)$ for purposes of analysis and a between-groups analysis of variance revealed a significant main effect of shock $(F=3.59, \quad \mathrm{df}=2 / 36, \quad \mathrm{p}<.05)$. The mean number of inductions required to elicit immobility was unaffected by shock, with means of $1.15,1.08$, and 1.08 for the control, low-shock, and high-shock groups, respectively.

\section{EXPERIMENT 2}

As a possible criticism of the preceding experiment, Gallup, Nash, Potter, \& Donegan (1970) suggested that shock applied to chickens might produce confounding physiological changes (e.g., tetany) which could, themselves, increase or exaggerate immobility. To circumvent this problem, they used loud noise as an alternate method of producing fear and found an enhanced immobility response resembling that produced by shock. Since increasing shock levels increased duration of immobility in the lizard, it was expected that exposure to a loud preinduction noise would likewise prolong the duration of immobility by increasing fear.

\section{Method}

The Ss were 20 mature anoles collected as in Experiment 1 and divided randomly into noise and no-noise groups. All lizards were maintained identically to those in the previous experiment.

A portable signal horn (Sears Aerosol Power Pack) which generated a low-frequency sound of $126 \mathrm{~dB}$, as measured by a General Radio 
sound-level meter (Model 1551-C), was used as the sound source.

To control for noise contamination, testing was conducted in a separate room. Due to the large within-group variability found in the first experiment, pretest habituation procedures were employed. On each of the 3 days prior to testing, each lizard was carried to the test room in its individual container and immobilized five times, with a 45-sec intertrial interval between successive inductions. If, on any habituation trial, the response lasted longer than $60 \mathrm{sec}$, it was terminated by gently prodding the animal.

On the day following the last habituation trial, each lizard in the noise group was individually carried to the test room and exposed to noise for $1 \mathrm{sec}$, with the horn held at a distance of $8 \mathrm{~cm}$ away. The $S$ was then immobilized and duration of immobility measured as in Experiment 1. Noise and no-noise Ss were tested alternately, and the procedure for the two groups was identical, except.that the horn was not sounded for $\mathrm{Ss}$ in the no-noise group. Results

Exposure to a loud noise had an appreciable effect on the resulting duration of immobility. The mean duration of immobility for the noise group was $404.2 \mathrm{sec}$ and only $94.8 \mathrm{sec}$ for the control group. A transformation $\left(\log _{10}\right)$ was performed on the raw data prior to analysis, and a between-group analysis of variance revealed a significant difference between the two groups $(F=5.02$, $\mathrm{df}=1 / 18, \mathrm{p}<.05)$.

\section{EXPERIMENT 3}

Working with chickens, Gallup, Nash, Donegan, \& McClure (1971) found that $S s$ restrained in the presence of a stuffed Cooper's hawk remained immobile considerably longer than controls. Similarly, Gallup, Cummings, \& Nash (1971) showed that chickens restrained in the presence of an $E$ remained immobile longer than those visually separated from the $\mathrm{E}$ by a plywood barrier. These findings fit in well with Ratner's (1967) suggestion that immobility reactions might have survival value under natural conditions and could have evolved in response to selective pressure exerted by predation. In line with this interpretation of animal hypnosis as a response to predation, it was hypothesized that the duration of tonic immobility in $A$. carolinensis would be increased by the visual presence of an $E$ and decreased when the $\mathrm{E}$ was concealed behind a barrier.

\section{Method}

The Ss were 12 mature anoles of both sexes obtained similarly to those in the previous experiments but maintained in the laboratory for only 1 day prior to testing.

The apparatus was a $50 \times 52 \mathrm{~cm}$ plywood barrier, with a small one-way wide-angle lens inserted in the middle, which was mounted on one side of the table used for induction.

Using the same procedure described by Gallup, Cummings, \& Nash (1971), half the Ss were restrained with the $E$ sitting in clear view (approximately $.6 \mathrm{~m}$ away from the $\mathrm{S}$ ), whereas for the remaining six lizards, the $E$ was hidden behind the plywood barrier. Results

The visual absence of an $\mathrm{E}$ proved to be an effective means of attenuating the immobility reaction. Mean duration of immobility was $834.8 \mathrm{sec}$ with the $E$ visible and only $169.8 \mathrm{sec}$ when the $E$ was concealed by the barrier. Using transformed ( $\left.\log _{10}\right)$ scores, a between-groups analysis of variance confirmed a significant difference between the two testing conditions $(F=7.27, \quad d f=1 / 10$, $\mathrm{p}<.025$ ).

As support for the fear hypothesis, in Experiment 1 the duration of tonic immobility in the lizard, $A$. carolinensis, was found to bear a reliable relationship to the amount of preinduction shock. These results parallel those where young chickens given shock prior to manual restraint remained immobile longer than no-shock controls and the results of Gallup, Nash, Potter, \& Donegan (1970) where duration of immobility varied as a function of shock intensity.

In the second experiment, lizards given brief exposure to a loud noise prior to induction remained immobile over four times longer than controls. The data from Experiment 2 are comparable to the finding (Gallup, Nash, Potter, \& Donegan, 1970) that loud noise, as a method of producing fear, increased the duration of tonic immobility in chickens. These results also correspond to those of Nash, Gallup, \& McClure (1970) where frogs (Rana pipiens) presented with a loud noise prior to restraint remained immobile longer than no-noise controls.

The finding of approximately an $80 \%$ reduction in the duration of immobility in lizards when the $E$ was concealed behind a barrier is likewise analogous to results obtained with chickens and supports the notion (Gallup, Cummings, \& Nash, 1971) that the E may be a potent source of variation in studies of animal hypnosis.

Contrary to the speculations of Prestrude \& Crawford (1970), who tend to favor a cortical inhibition account, these three experiments with A. carolinensis provide direct support for a fear interpretation of animal hypnosis in lizards. Additional support is provided by data from the third experiment for the notion that the presence of a potential predator can substantially influence the hypnotic response. Thus, conceptualizing tonic immobility as a fear response, which under natural conditions may be related to predation, appears to hold up well across several species and is not restricted to the domestic chicken.

\section{REFERENCES}

GALLUP, G. G.. JR., CREEKMORE, H. S., \& HILL, W. E., III. Shock-enhanced immobility reactions in chickens: Support for the fear hypothesis. The Psychological Record, 1970, 20, 243-245.

GALLUP, G. G., JR., CUMMINGS, W. H., \& NASH, R. F. The experimenter as an independent variable in studies of animal hypnosis in chickens (Gallus gallus). Animal Behaviour, 1971, in press.

GALLUP, G. G., JR., NASH, R. F., DONEGAN, N. H., \& MCCLURE, M. K. The immobility response: A predator-induced reaction in chickens. The Psychological Record, 1971, in press. GALLUP, G, G., JR .. NASH, R. F.. POTTER, R. J., \& DONEGAN, N. H. Effect of varying conditions of fear on immobility reactions in domestic chickens (Gallus gallus). Journal of Comparative \& Physiological Psychology, $1970,73,442-445$.

GALLUP, G. G., JR., ROSEN, T. S., \& BR OWN. C. W. Effect of conditioned fear on tonic immobility in domestic chickens. Journal of Comparative \& Physiological Psychology, 1971, in press.

HOAGLAND, $\mathrm{H}$. The mechanism of tonic immobility ("animal hypnosis"). Journal of General Psychology, 1928a, 1 . 426-447.

HOAGLAND, $H$. On the mechanism of tonic immobility in vertebrates. Journal of General Psychology, 1928b, 11, 715-741. NASH, R. F., GALLUP, G. G., JR.. \&
MCCLURE, M. K. The immobility reaction in leopard frogs (Rana pipiens) as a function of noise-induced fear. Psychonomic Science, 1970, 21, 155-156.

PRESTRUDE, A. M., \& CRAWFORD, F. T. Tonic immobility in the lizard, Iguana iguana. Animal Behaviour, 1970, 18. 391-395.

RATNER. S. C. Comparative aspects of hypnosis. In J. E. Gordon (Ed.), Handbook of clinical and experimental hypnosis. New York: Macmillan, 1967. Pp. 550-587.

RATNER, S. C., \& THOMPSON, R. W. Immobility reactions (fear) of domestic fowl as a function of age and prior experience. Animal Behaviour, 1960, 8, 186-191.

SALZEN, E. A. Imprinting and the immobility reactions of domestic fowl. Animal Behaviour, 1963, 11, 66-71. 